\title{
Crear más vida, más sentido, más mundo. La clase de religión como acto de resistencia
}

\author{
Lidia Troya Cáceres
}

\section{Resumen}

La educación es reflejo privilegiado de cada momento cultural. Ante una sociedad ensordecida por la técnica, el rendimiento o lo pragmático, que plantea un modelo de ser humano y, por ende, de alumnado, encumbrado hacia el éxito, y que no atiende al cuidado ni a la hondura de la persona, urge proponer la clase de religión como un acto de resistencia, donde los más jóvenes puedan encontrar y crear más vida, más sentido y más mundo. Tras analizar cómo afecta el paradigma del progreso a la escuela y señalar algunos aspectos de la concepción y la praxis más tradicional de la clase de religión que se han de superar, se propondrán tres claves a tener en cuenta, que permitan contrarrestar y reivindicar lo valioso de la ERE (Enseñanza Religiosa Escolar) en la cultura de nuestro tiempo.

\section{Palabras clave}

ERE, sistema educativo, sociedad, progreso, sentido, religión, persona.

\section{Introducción}

Vivimos en la sociedad de los logros. La técnica, la meritocracia o el utilitarismo se han adueñado también de la enseñanza y del sistema educativo, con su propuesta de ser humano encumbrado hacia el éxito. Sin embargo, como personas no nos basta con vivir, sino que hemos de amar la vida que vivimos. Ante la inconsistencia y

1 Profesora del Área de Ciencias de la Religión de La Salle Campus Madrid. Licenciada en Ciencias Catequéticas y Religiosas. Escucha y acompañante en duelo y en abusos. 
la desintegración a la que el alumnado se ve sometido, mantener viva la pregunta por la existencia, ahondar en el sentido y hacer del mundo más mundo parece fundamental. La clase de religión es una oportunidad para acompañar las necesidades que emergen del fondo de lo humano, para elaborar otros cimientos y para buscar otras estrategias educativas más próximas al conocimiento de sí mismo, al cuidado y a la atención. Ahora bien, no cualquier clase de religión².

Tras analizar cómo afecta el paradigma del progreso a la escuela y señalar algunos aspectos de la concepción y la praxis más tradicional de la clase de religión que se han de superar, se propondrán tres claves a tener en cuenta, desde mi experiencia como docente, que permitan contrarrestar y reivindicar lo valioso de la ERE (Enseñanza Religiosa Escolar) en la cultura de nuestro tiempo.

\section{La escuela, lugar donde se recibe el pulso de la vida}

Edgar Morin, en 1999, hablaba de los siete saberes necesarios para la educación del futuro3. El filósofo, sociólogo y político partía de la idea de que existen siete vacíos profundos en el ámbito de la pedagogía docente que son ignorados, ocultados o desintegrados en fragmentos. Hemos cambiado de siglo, pero el vacío parece mayor. Las matemáticas, la lengua y el inglés vertebran nuestro sistema educativo, pero ¿quién o qué vertebra a los alumnos? ¿Desde dónde se están diseñando las propuestas educativas? ¿Qué las sostiene? Y, sobre todo, ¿qué idea de ser humano, de educando, de vida, se tiene y se quiere proponer?

La educación es reflejo privilegiado de cada momento cultural. Hoy los saberes científico-técnicos y una forma determinada de racionalidad, al servicio de las eficiencias sociales y pragmáticas, se va apoderando también de modo sutil de nuestro sistema educativo. Pero no podemos dejar que la vida de nuestros alumnos la dirija un algoritmo. En una sociedad como la actual, con un proceso educativo encumbrado también hacia los logros, la clase de religión - no cualquiera- debiera ser un acto subversivo. Finlandia, "faro educativo" durante años en

2 El nuevo Curriculum de la ERE va a ofrecer muchas posibilidades para seguir acercando la clase de religión a los alumnos de hoy y adaptarla al momento actual.

3 E. Morin, Los siete saberes para la educación del futuro, Paidós, Barcelona 2001. 
Europa, apuesta por la religión para prevenir la violencia en las aulas. Sin embargo, en España, el sindicato de profesores de Religión PREC denuncia el "el acoso y el progresivo arrinconamiento" que ha sufrido la materia en el sistema educativo en los últimos años ${ }^{4}$.

Educar no es ayudar a tener una carrera para ganarse la vida, sino templar el alma para las dificultades de la vida, que no son pocas. En el claroscuro de la existencia, conocerse a sí mismo es lo más difícil, como afirma Tales de Mileto 5 , y, sin embargo, es necesario. Pero ¿en qué espacio del colegio se dedica tiempo a esta importante tarea? ¿Dónde se habla de lo propiamente humano? ¿Dónde se aprende a explorar lo más hondo, el subsuelo de la existencia humana, sabiendo que ese es uno de los lugares privilegiados donde irrumpe lo divino?

El utilitarismo de la enseñanza y del sistema educativo es lamentable. Nuccio Ordine advierte del gravísimo error que supone para la educación aceptar la lógica neoliberal'. Por su parte, Marina Garcés denuncia la "servidumbre adaptativa" de la educación? . La filósofa no aboga ni por las viejas formas que concebían la educación como algo rígido y jerárquico, ni tampoco por la alternativa promovida por el neoliberalismo, es decir, el entrenamiento constante y la flexibilidad, la capacidad permanente de cazar oportunidades y el hecho de pensarse a sí mismo como un potencial en constaste aumento.

El progreso y la digitalización del mundo se han convertido en la nueva religión, con consecuencias evidentes en la comunidad educativa y con un alto impacto sobre el alumnado, porque los discursos de la sociedad afectan al modo en el que las personas interpretan la realidad y, por tanto, actúan. El diluvio de información deja al alumnado atrapado en la red y al profesor en los contenidos. Demasiada información y poca

4 E. Armora, "Finlandia apuesta por la Religión para prevenir la violencia en las aulas", $A B C$ (13.10.2021).

5 Según Diógenes Laercio, preguntado Tales de Mileto sobre qué era lo más difícil, éste respondió: 'el conocerse a sí mismo'. Diógenes Laercio, Vida y opiniones de los filósofos ilustres, Alianza, Madrid 2007, \$1.36, p. 50.

6 N. Ordine, Clásicos para la vida: una pequeña biblioteca ideal, Acantilado, Barcelona 2017, 6 ed. N. Ordine, Una escuela para la vida, Universidad Valparaíso, Valparaíso 2014.

7 M. Garcés, Nueva ilustración radical, Anagrama, Madrid 2017. 
comprensión está generando un nuevo tipo de analfabetismo. Recuerda Leda Muñoz que la forma en la que se navega por las redes fomenta un pensamiento superficial y artificial ${ }^{8}$.

La escuela es un espacio de crecimiento íntimo y colectivo, es el lugar donde primero edificamos el futuro ${ }^{9}$. ¿Qué futuro? Con frecuencia cunde la desesperanza no solo en los alumnos, sino también entre los educadores, tan cargados de trabajo, tan agotados y con desconfianza en el presente. Byung-Chul Han ${ }^{10}$ crítica esta forma de los adultos de estar en el mundo y de vivir en la sociedad, en la que el sujeto es como el Prometeo cansado, que lleva a cumplir con las exigencias que se imponen a sí mismos en una continua condena de autoexplotación. La modernidad hizo creer que el ser humano podía emprender cualquier empresa y ocupar el lugar que deseaba, declarando ilegítimas todas las limitaciones. Sin embargo, bajo la retórica del progreso, las víctimas no han dejado de amontonarse escandalosamente en las cunetas, porque, tal y como postura Luis Aranguren: "ni el crecimiento económico indefinido, ni el consumo desaforado, ni la explotación de los recursos naturales, ni la mercantilización de la vida nos conducen al cuidado necesario"". El ser humano, siendo capaz de lo más hermoso, es también un individuo que puede destruirse a sí mismo ${ }^{12}$.

Se ha construido un mundo en el que se elimina lo que no es útil ni sirve, lo que no responde a los intereses y criterios de eficiencia 0 empleabilidad, lo que no tiene fuerza. Socialmente se está sometido a un imaginario: "si te esfuerzas te irá bien". La meritocracia, tan presente también en nuestros sistemas de evaluación, vuelve a las personas competitivas, disminuyendo la capacidad para la solidaridad y el bien común. Así lo expresa M. Sandel, premio Princesa de Asturias de ciencias sociales 2018:

8 L. Muñoz García, "Mucha información, poca comprensión: un nuevo tipo de analfabetismo", El financiero, (20.05.2021).

9 I. Vallejo, "Nubes", Milenio (03.09.2021)

10 B.-C. Han, La sociedad del cansancio, Herder, Barcelona 2012, 9.

11 L. Aranguren, Es nuestro momento. El paradigma del cuidado como desafí educativo, Fundación SM, Madrid 2020, 64.

12 J. Urabayen, "El humanismo trágico de Gabriel Marcel: el ser humano en un mundo roto", Estudios de Filosofí 41 (2010) 35-59. 
"La idea de que el sistema premia el talento y el trabajo anima a los ganadores a considerar que su éxito ha sido obra suya, un indicador de su virtud, y a mirar con condescendencia a quienes no han sido tan afortunados como ellos (...). La soberbia meritocrática refleja la tendencia de los ganadores a dejar que su éxito se les suba demasiado a la cabeza, a olvidar lo mucho que les han ayudado la fortuna y la buena suerte. Representa la petulante convicción de los de arriba de que se merecen el destino que les ha tocado en suerte y de que los de abajo se merecen también el suyo"13.

En la actualidad impera la idea de que todo puede resolverse tecno-científicamente. La sociedad tecnificada lo reduce todo a problema, es decir, que, en nombre del progreso y la razón, hay una técnica que ayuda a superar todos los obstáculos. Evgeny Morozov define el solucionismo tecnológico como la:

"ideología que legitima las aspiraciones de abordar cualquier situación social compleja a partir de problemas de definición clara y soluciones definitivas. La complejidad es reducida a un conjunto de variables, a partir de las que se elaboran modelos predictivos"14.

Si se pierde la capacidad de elaborar los problemas verdaderos y de transitar por el misterio, se cae en manos de falsos problemas, influencers y vendedores de recetas. En la utopía solucionista ${ }^{15}$ los humanos podrán ser estúpidos, porque el mundo mismo será inteligente.

En este contexto es necesario preguntarse: ¿Cuál es la verdadera misión de los centros escolares? ¿Para qué educamos? ¿Educamos para formar personas críticas, cultas, con conciencia civil, gusto por la vida y capacidad para obrar y embellecer el mundo o para formar futuros trabajadores y empleadores que sigan alimentando el sistema? Los dos propósitos de cualquier sistema educativo tendrían que ver con los dos grandes anhelos del ser humano, que son, como ya postulaba Aristóteles en la antigüedad, la felicidad y la sociedad justa ${ }^{16}$. La enseñanza de la religión

13 M. J. Sanders, La tiranía del mérito ¿Qué ha sido del bien común?, Debate, Madrid 2020, 58.

14 E. Morozov, La locura del solucionismo tecnológico, Clave Intelectual, Madrid 2015, 166.

15 K. G. Liberal y E. Rodríguez, "Apocalipsis o solucionismo", ctxt (contexto y acción) 184 (2018).

16 O. Ponsatí-Murlà, Aristóteles: el hombre feliz y la sociedad justa son los que buscan el equilibrio entre los extremos, RBA, Barcelona 2015. 
engarza perfectamente con todos los objetivos pedagógicos de la historia de España y con los actuales. La religión no es solo un tema de la iglesia, mucho menos un privilegio suyo, es un tema de la educación y de la condición humana. La ERE no desatiende los anhelos de felicidad y justicia de la sociedad plural y secularizada en la que vivimos. Como se verá, la formación religiosa, junto con la filosofía, ayuda a modelar en el alumno una parte de su persona que otras materias no cuidan y que la escuela tiene que educar. Si la clase de religión no está, ¿dónde se van a acompañar aquellos temas que tienen que ver con el sentido de la vida, las preguntas fundamentales y el anhelo de plenitud del ser humano?

En el foro Europeo sobre la Enseñanza de la Religión, la inteligencia espiritual fue propuesta como un tesoro escondido para la persona y un bien común mundial para la sociedad, tal y como afirma Carlos Esteban Garcés $^{17}$. Ésta, que es un rasgo de identidad de la clase de religión, nos faculta para preguntar por el sentido de la existencia, para tomar distancia de la realidad, para elaborar proyectos de vida, para trascender la materialidad, para fortalecer el ámbito de lo penúltimo, del asombro, de la admiración, de la experiencia estética, para interpretar símbolos y comprender sabidurías de vida. Aprender a ser más humanos, en una era donde el progreso nos arroja a un futuro tremendamente incierto y cerrado, parece acuciante. Una escuela que no ofrezca espacios para el sosiego, para la búsqueda de sentido y oportunidades para adentrarse en el Misterio, de lo divino y de lo humano, será una escuela que no cumpla con su papel esencial.

\section{Desacralizar la clase de religión}

El tiempo en el que la enseñanza de la religión era obligatoria ha pasado, sin embargo, pese a la evolución y a la transición de una enseñanza religiosa próxima al catecismo a una enseñanza escolar dotada de un currículo académico, la imagen de la religión como una dimensión sobrenatural, ajena a la vida, separada de la realidad y de

17 C. Esteban Garcés, "Punto de vista. Despertar la inteligencia espiritual", Religión y Escuela 320 (2018) 15. F. Torralba la define como una modalidad de inteligencia que también se denomina existencial o trascendente y que completa el mapa de las inteligencias múltiples que desarrolló Gardner. Cf. F. Torralba, La interioridad habitada, Khaf, Madrid 2019. 
la que se puede casi prescindir, persiste en parte del imaginario social y educativo. El malestar religioso de nuestro tiempo ${ }^{18}$ convive con el desgaste de la clase de religión, pese al compromiso y a la excelente labor de muchos profesores. Los alumnos, aun optando por ella desde pequeños, no parecen percibir el valor de esta materia y algunos centros educativos, pese a ser religiosos, tampoco.

Hay quienes elevan tanto lo divino, que, a menudo, carece de valor en la tierra y escapa a lo humano, no generando interés. En el otro extremo se sitúan quienes parecen poseer de modo clarividente los contenidos propios para acceder al núcleo de la revelación, de modo que la clase de religión es un pseudónimo de catequesis dogmática y doctrina, pero reducir la clase de religión a adoctrinamiento es profanar la religión y la vida. La fe no es un sistema religioso, sino un camino a recorrer. Por fortuna para los más jóvenes la fe ya no es una obligación, ni algo con lo que haya que cumplir, como lo sigue siendo para no pocos cristianos practicantes.

Ante las categorías religiosas más tradicionales los alumnos tienen dificultades, como los propios compañeros y, por qué no decirlo, los propios cristianos ${ }^{19}$. Para los nacidos en este siglo, incluso en una familia religiosa ${ }^{20}$, es rara avis quien tiene una tradición cristiana inteligible. Nuestros alumnos son ignorantes en el tema religioso, porque no tienen noticia de él y las noticias que les llegan no les convencen. La mayor parte de ellos son indiferentes, no ateos, y se sitúan "al margen de" porque la religiosidad oficial no parece responder a las necesidades y búsquedas de las personas de hoy. Se han socializado en la increencia, aunque les hayan bautizado y hayan hecho la comunión. De ahí la necesidad de traducir el lenguaje religioso al mundo laico y a las categorías antropológico existencias ineludibles para toda vida.

18 J. Martín Velasco, El malestar religioso de nuestra cultura, Paulinas, Madrid 1993.

19 "Al goteo imparable de deserciones internas se una la dificultad de la institución eclesial para representar una esperanza para los hombres y mujeres de hoy". Grupo Erasmo, "La Iglesia que amamos, vivimos y soñamos", Vida Nueva 3.239 (2021) 23-30, 24.

20 La educación religiosa no le pertenece solo al colegio, sino principalmente a la familia. Es muy difícil contrarrestar, con una sola hora de clase de religión a la semana, aquello que no se recibe en casa y que tampoco transmiten las redes sociales, en las que los adolescentes pasan horas y horas. 
Evangelizar es traducir, no adoctrinar ni ganar prosélitos. La religión apunta a realidades que siguen siendo contemporáneas, porque Dios es la Luz, el Amor, la Vida, el motor y la plenitud para muchos. Con la Biblia ${ }^{21}$ también sucede que la mayoría la encuentra lejana y ajena. ¿Es posible que la Palabra de Dios siga resonando hoy? Nuestras experiencias, pese al paso del tiempo, están entretejidas en las vivencias del pueblo de Israel, ya que el corazón humano es siempre el mismo. La palabra de Dios sigue teniendo significado para las vidas y las personas de hoy, porque, como afirma Dolores Aleixandre "esta historia es mi historia"22.

Tristemente, muchas personas siguen ancladas en el paradigma religioso de antaño, desconocedoras del Concilio Vaticano II y del cambio que supuso para la Iglesia. La comunidad educativa y los propios alumnos viven de una imagen de la clase de religión que no es la actual, porque no les hemos acompañado en el viaje y en la transición de una fe medieval a una fe actual, ni en los cambios de la Iglesia ni de la sociedad. Los "signos de los tiempos" ponen de manifiesto que los tiempos cambian, que la cultura evoluciona y que nosotros debemos cambiar continuamente, sin miedo y con libertad. A veces, se transmiten imágenes y concepciones medievales con tanto amor que parece de valientes, pero que no consiguen conectar con los jóvenes del siglo XXI ni ser fieles al mensaje original de Jesús.-

En esta controversia cultural y política en la que vivimos, la ERE ha de situarse lucidamente, es decir, sacando luz. Ello supone acoger cordialmente, es decir, desde el corazón, esta cultura sabiendo que es secularizada y plural, lo cual no es malo. De hecho, la secularización, de la que muchos se lamentan, permite dejar atrás adherencias que parecían importantes, pero que en el fondo no lo son. Dentro del marco escolar, también multicultural e interreligioso, el lugar del saber religioso no es el lugar del encontronazo, sino del encuentro, por lo que el tono de la ERE debe ser la suavidad, el tiento, como el que cul-

21 El método Godly Play ayuda, a adultos y a niños, a acercarse a los relatos bíblicos de una manera desacostumbrada. J.A. Sánchez Abarrio, "La Biblia al servicio de la espiritualidad de la infancia", Sinite 62:187 (2021) 13-36.

22 D. Aleixandre, Esta historia es mi historia: narraciones bíblicas vividas hoy, CCS, Madrid 1997. 
tiva el campo. Para obtener una visión positiva de la enseñanza de la religión, también en los sistemas educativos democráticos, hemos de renovar a fondo las relaciones de las personas con el Misterio, posibilitando el encuentro de nuestros alumnos con Dios y con Jesús. El objetivo de la clase de religión no es que los alumnos sean creyentes o que se conviertan, porque ni siquiera se dirige solo a los católicos, ni se hace un trabajo de convocatoria a la comunidad cristiana.

La ERE debería ayudar a los alumnos a que perciban que vivimos para mejorar el mundo, cambiar la sociedad, construir la casa común y lo hacemos desde una experiencia creyente que no se puede imponer a nadie y que se ha de compartir con naturalidad y frescura. Tenemos que hacernos cargo de una nueva realidad en la que la Iglesia sea tienda de campaña y atrio de los gentiles para que las nuevas generaciones puedan descubrir a Dios. Como quien se sabe regalado, tendremos que tener muy presente que la religión no es lo mejor, pero es aquello que nos conquistó el corazón, que nos mueve, que nos constituye, que somos y por eso merece un lugar.

No se puede pretender tener a niños y jóvenes del siglo XXI en aulas de los ochenta. La figura del profesor bondadoso y comprometido, pero sin formación y sin titulación en esta área, que aún convive en algunos centros educativos, concertados y privados, puede incidir de manera negativa en el itinerario creyente del futuro adulto. El perfil del profesor de religión es distinto a otros profesores, porque la religión no es como las demás materias, y no se puede transmitir sin la vivencia religiosa, pero se necesita también un alto nivel de cualificación profesional inicial y permanente. La buena voluntad del educador no es suficiente para acabar con la infantilización de la fe y de la clase de religión.

Para devolver la dignidad a la enseñanza religiosa en los centros educativos y, por ende, al profesorado que imparte esta materia, es necesaria una formación seria y rigurosa que evite la ñoñería de la fe y que las piedades disparatadas o las creencias distorsionadas perviertan, en nombre de Dios, la relación del alumno consigo mismo, con la propia Iglesia y con el mismo Dios. El departamento de religión, junto con el de pastoral, tendrá que trabajar en una pro- 
puesta que lleve a desprenderse de las falsas creencias ${ }^{23}$ heredadas que aún perviven en el inconsciente colectivo, así como a dejar atrás aquella mentalidad religiosa que pretende apoderarse del Misterio y que divide el mundo entre creyentes y no creyentes, entre buenos y malos o entre salvados y condenados.

La religión está llamada a ser puente, vehículo del espíritu, nunca obstáculo. La ERE tiene forma de camino, de construcción colectiva y de espera; no busca vencer ni convencer, ni señalar con el dedo. La persona verdaderamente religiosa no juzga como inauténtica la vida de los demás y reconoce el bien que también existe en los lugares alejados de la $\mathrm{fe}^{24}$, por lo que se ha de prestar atención a aquellas ideologías ${ }^{25}$ que se dicen cristianas, que se están colando en algunas aulas, y que no llevan a una experiencia creyente, sino de escisión y deshumanización. Hablar con sentido de Dios solamente es posible sobre la base de experiencias humanas, sobre la praxis de la justicia y del amor y sus implicaciones.

23 Mardones propone "matar a nuestros dioses", como ejercicio previo y necesario para acercarse al "Dios verdadero". Habla de algunas imágenes idólatras de dios, que se han de combatir decididamente, porque hacen daño y son un caldo de cultivo para la persona que no es creyente o, incluso, para sofocar la fe de la persona creyente que piensa. J. M. Mardones, Matar a nuestros dioses. Un Dios para un crejente adulto, PPC, Madrid 2005.

24 Ya en 1965 Dignitatis Humanis proclamaba la libertad religiosa: el ser humano es libre para creer o no creer y puede ser feliz y luchar por un mundo más justo y mejor, creyendo y no creyendo.

25 El papa Francisco advierte en su carta encíclica sobre la fraternidad y la amistad social Fratelli tutti que "la historia da muestras de estar volviendo atrás. Se encienden conflictos anacrónicos que se consideraban superados, resurgen nacionalismos cerrados, exasperados, resentidos y agresivos. En varios países una idea de la unidad del pueblo y de la nación, penetrada por diversas ideologías, crea nuevas formas de egoísmo y de pérdida del sentido social enmascaradas bajo una supuesta defensa de los intereses nacionales" (n. 11). Y continua diciendo, ante los fanatismos y el arrinconamiento de los migrantes que "es inaceptable que los cristianos compartan esta mentalidad y estas actitudes, haciendo prevalecer a veces ciertas preferencias políticas por encima de hondas convicciones de la propia fe: la inalienable dignidad de cada persona humana más allá de su origen, color o religión, y la ley suprema del amor fraterno (n. 39). En esta misma línea, el teólogo J. J. Tamayo ha acuñado el término de "cristoneofascismo". Cf. J. J. Tamayo, La Internacional del odio, Icaria, Valencia 2020. 


\section{Habitar lo humano. Claves para resignificar lo religioso en las aulas de hoy}

Ser humano no significa ir más allá de lo humano, como propone la técnica y el transhumanismo, sino intensificar lo humano y su sentido $^{26}$. El horizonte más importante no se encuentra más allá, ni más lejos, sino más adentro. Los saberes sobre la hondura y la base de la vida son propios de la ERE. La religión está hecha de raíces y aprendizajes de lo invisible, porque así es el Dios de Jesús, que nos cimienta y enraíza, y porque "no estamos huecas por dentro", como decía la santa de Ávila ${ }^{27}$ a las novicias para hacerlas caer en la cuenta de que el misterio habitaba su interioridad.

Las raíces vertebran nuestra vida, nos dan sustento, nos nutren, nos yerguen. Dice la pensadora Simone Weil que:

"echar raíces quizá sea la necesidad más importante e ignorada del alma humana. Es una de las más dificiles de definir. Un ser humano tiene raíces en virtud de su participación real, activa y natural en la vida de una comunidad que conserva en su forma viva ciertos tesoros específicos del pasado y ciertas expectativas específicas para el futuro ${ }^{28}$ ".

El arraigo es una relación entre el individuo y una comunidad, entre el pasado y el futuro, entre la tierra y el cielo. El estrato más profundo de la persona está formado por creencias e ideales ${ }^{29}$ y la religión en la escuela apunta al arraigo, a esas creencias nucleares que conforman el cimiento que va a sostener toda la personalidad humana. ¿Cómo no tenerla presente en los planes educativos? ¿Cómo no suscitar una

26 Cf. J. M. Esquirol, Humano, más humano. Una antropología de la herida infinita, Acantilado, Barcelona 2021.

27 Teresa de Jesús, Obras completas de Santa Teresa de Jesús, BAC, Madrid 2006, 9 ed.

28 S. Weil, Echar raices, Trotta, Madrid 1996, 43.

29 El filósofo Ortega y Gasset afirma que "las creencias constituyen la base de nuestra vida, el terreno sobre el que acontece. Porque ellas nos ponen delante lo que para nosotros es la realidad misma. Toda nuestra conducta, incluso la intelectual, depende de cuál sea el sistema de nuestras creencias auténticas. En ellas vivimos, nos movemos y somos. Por lo mismo, no solemos tener conciencia expresa de ellas, no las pensamos, sino que actúan latentes, como implicaciones de cuanto expresamente hacemos o pensamos". J. Ortega y Gasset, Ideas y creencias, Vol 5, Obras completas, Alianza, Madrid 1983, 34. 
infraestructura humano-espiritual que vertebre y prepare desde lo propio de la condición humana para un posible encuentro con la fe?

La ERE es ante todo una asignatura, dentro del marco pactado entre la Iglesia y el estado, del currículum oficial ${ }^{30}$ de nuestro sistema educativo y, como tal, prescribe y norma lo que en la clase de religión se debe enseñar. En ella se pretende acercar al alumno a las principales claves de la fe cristiana y de la revelación, presentar el hecho religioso y el conocimiento de distintas religiones, iluminar el sentido de la vida y dialogar entre la fe y la cultura. Más allá de las competencias y los contenidos del curriculum, vamos a atender a tres claves, transversales a toda la propuesta educativa de la enseñanza religiosa escolar, que no están formuladas en los documentos y que, desde mi experiencia como docente, son importantes para re-vitalizar y resignificar la religión en las aulas hoy, porque la ERE, como la teología encarnada, es capaz de intensificar la vida, de dar sentido y de obrar mundo. En este sentido, la clase de religión es un acto de resistencia, íntima y colectiva, porque favorece una comprensión dialéctica, crítica y re-creativa de uno mismo, del otro -Otro- y del mundo que nos ha tocado vivir.

\subsection{Crear más vida}

Como humanos no nos basta con vivir, sino que hemos de amar la vida que vivimos. La religión existe precisamente porque tenemos que vivir. Hay quienes creen, junto con los maestros de la sospecha, que la clave de lo religioso es el miedo a la muerte, pero el motor de ésta no debe ser la impotencia, sino la pasión por la vida y así se lo hemos de trasmitir a los alumnos. La clase de religión es un regalo muy valioso, porque proporciona espacios y herramientas para plantearse lo más interesante de la vida, que es la vida misma. A continuación, nos fijaremos en cuatro actitudes que pueden contribuir a intensificar la vida.

30 El marco de la Enseñanza religiosa está regido por el Curriculum oficial aprobado por el ministerio de Educación y, entre otros documentos, por el documento Orientaciones Pastorales sobre la enseñanza religiosa escolar de la Comisión Episcopal de Enseñanza y Catequesis de 1979. 


\subsubsection{Los ritos y la razón poética}

Los ritos hacen que el tiempo y el espacio sean distintos. Más allá de lo conceptual y la razón instrumental, predominante en nuestra sociedad y en nuestras metodologías, la narración, la metáfora y lo simbólico, abren posibilidades, esponjan y permiten a los alumnos situarse internamente en otro lugar menos árido. El pensamiento como creación simbólica, orienta y revitaliza.

El lenguaje religioso es propicio para abandonar el intelectualismo que penetra la realidad para comprenderla, explicarla y, por tanto, dominarla, para tan solo recibirla. Los alumnos necesitan más razón poética que les con-mueva y desexplique lo inexplicable, porque más hondo de lo representable y categorizable late la existencia. Apostar por ella y por dinámicas donde, además de la palabra, se integren el silencio, la música, la contemplación de alguna imagen que evoque belleza y los símbolos, es una buena manera de convertir la clase en una pequeña liturgia, que haga presente el kairos en el cronos y que acabe con la acumulación del tiempo sin más o la funcionalización de la existencia.

Los gestos animan y encienden la vida. Lo celebrativo también hace crecer lo vivido. ¿Por qué no aprovechar algunos momentos, como el inicio o el final de curso, para reconocer y agradecer con ellos? Los más jóvenes esperan tenerlo todo. La auto-exigencia y el continuo esfuerzo expulsa del ser humano toda sensación de estar bendecidos por don o gracia algunos, pero la clase de religión es también lugar para propiciar la circularidad de la acogida y la donación.

\subsubsection{Cuerpo, emoción y corazón}

La ERE reclama un tipo de aprendizaje que afecta a toda la persona. Los alumnos no se desarrollan solo en la mente; somos espíritu o corazón profundo, psique y cuerpo. La clase de religión es un lugar privilegiado para experimentar que, además de la reflexión y el pensamiento, nos constituyen el cuerpo, la emoción y la trascendencia.

El cristianismo es la religión de la encarnación y de la resurrección de la carne. El amor y el Evangelio solo se hacen posible en el cuerpo que 
somos; la Palabra se hace cuerpo en nuestro cuerpo, con lo que cada parte del mismo es y simboliza. A menudo, las confusiones históricas han convertido el cristianismo en un platonismo para el pueblo y también para nuestros alumnos adolescentes. Sin embargo, frente a los dualismos milenarios que han configurado gran parte de la espiritualidad cristina, la clase de religión es una oportunidad para enseñar a los más jóvenes que somos "carne animada" o "cuerpo viviente" y templo: "El cuerpo expresa a la persona. No es solo un objeto, sino fundamentalmente alguien (...). Es el aliento que soporta el pensamiento, el cuerpo remite a la existencia entera del ser humano" ${ }^{31}$. La adolescencia es una época de descubrimiento del cuerpo. ¿Por qué no educar en una espiritualidad sentida y proponerles itinerarios, a través del cuerpo, para saborear a Dios, oír a Dios, sentir a Dios, ver a Dios y gozar con Dios? ${ }^{32}$

De esta manera, la ERE puede contribuir a la unificación, propiciando también el diálogo con el propio corazón: "Hijo mío, cuida tu corazón, en el están las fuentes de la vida" (Prov 4,23). El asentimiento de la fe responde a las aspiraciones presentes en el propio corazón y en el latido de la experiencia humana. Ante la continua ex-troversión a la que se ven sometidos los estudiantes, el corazón es el lugar del encuentro, el centro del ser, donde se es uno. En el corazón mora el misterio, humano y divino, y reside la fuente de la que bebemos.

\subsubsection{La escucha}

La velocidad cansa y el ruido nos distrae. La clase de religión es una oportunidad para detener el ritmo de las tareas y escuchar el ritmo de la Vida. Los alumnos están extenuados ante el ritmo vertiginoso del plan de estudios y las actividades extraescolares. La rapidez hace que también perdamos cada vez más la capacidad de escuchar a otros y de atender a su lenguaje, a su sufrimiento, a sus miedos. ByungChul Han afirma que, ante la dificultad de escuchar, en el futuro habrá posiblemente una profesión que se llame oyente:

31 Cf, O. Clement. Teopoética del cuerpo. Sígueme, Salamanca, 2017, 10.

32 A este respecto, es muy interesante la propuesta práctica de Emma Martínez Ocaña. Cf. E. Martínez, Cuando la palabra se hace cuerpo... en cuerpo de mujer, Narcea, Madrid 2007. 
"A cambio del pago, el oyente escuchará a otro atendiendo lo que dice. Escuchar no es un acto pasivo. Se caracteriza por una actividad peculiar. Primero tengo que dar la bienvenida al otro, es decir, tengo que afirmar al otro en su alteridad. Luego atiendo a lo que dice. Escuchar es un prestar, un dar, un don... El silencio brinda hospitalidad e invita al otro a liberarse hablando. La actitud responsable del oyente hacia el otro se manifiesta como paciencia. La pasividad de la paciencia es la primera máxima de la escucha ${ }^{33}$ ".

Existimos en relación y uno se transforma por la vivencia de encontrarse con un tú (y un Tú). Proponer hoy la fe en las aulas no es tanto enseñar contenidos, cuanto acompañar a los alumnos en lo que viven, sugerirles itinerarios de vida e invitarles a dar algunos pasos en el sentido del Evangelio. Para Esquirol, la escucha es como el tacto. Saber escuchar es dejarse tocar ${ }^{34}$, de modo que quedarse corto en humanidad se descubre como falta de tacto, como frialdad, como indiferencia. Una de las letanías que habría que repetir en la clase de religión es que lo contrario de la receptividad es cierre y el cierre es indiferencia y la indiferencia es muerte, pecado.

\subsubsection{La apertura al otro}

El amor y la apertura al otro forman parte del gusto de la vida. El diálogo y la unidad entre la fe y las distintas culturas constituye uno de los objetivos fundamentales de la educación cristiana. Ante la exigencia de vivir juntos en clases y en sociedades cada vez más multiculturales, la ERE como disciplina escolar abierta al re-conocimiento del otro, al respeto de las diferencias y a la comprensión de diversas posturas existenciales es muy relevante. Tanto como el amor y el respeto hacia los propios alumnos.

Educar es amar. El afecto nos moviliza, nos recrea, mientras que el juicio nos paraliza. Las neurociencias avalan que los humanos no aprendemos bien salvo que nos sintamos suficientemente seguros y regulados afectivamente ${ }^{35}$. Las personas sabias y espirituales de todas las épocas se caracterizan por el bien que hacen, por el espa-

33 B.-C. Han, La expulsión de lo distinto, Herder, Barcelona 2017, 113-114.

34 Esquirol, Humano, más humano, 58.

35 Cf. D. J. Siegel, La mente en desarrollo. Cómo interactúan las relaciones y el cerebro para modelar nuestro ser, Desclée de Brouwer, Bilbao 2007. 
cio que abren y por la confianza que dan. La presencia del educador cristiano, lejos de convertirse en funcionario del hecho religioso, tiene que ser expresión de incondicionalidad, cercanía y verdad. Los adolescentes no están tan perdidos como, a veces, nos decimos, desanimados, en los claustros. Es necesario ayudarles a valorar las posibilidades que llevan dentro de sí como dinamismos y deseo positivo, y acompañarles en el alumbramiento de la verdad que mora en ellos.

C. Yushimito define bellamente la docencia como un acto de compa$\tilde{n} i ́ a^{36}$. El acompañamiento a los alumnos debería ser un eje vertebrador de toda la acción educativa, especialmente desde el ámbito de lo religioso. Acompañar, del latín "cum panis", tiene relación simbólica con lo que podríamos expresar como "comer pan juntos", es decir, sentarse a la mesa de sentido del otro, e intercambiar cuanto hay en ella: sentimientos, deseos, preocupaciones, gozos y esperanzas ${ }^{37}$. La escucha y la apertura al otro es un regalo que da consistencia a la vida y confianza para mantenerse en pie.

\subsection{Crear más sentido}

Una segunda clave tiene que ver con el sentido. El ser humano es un relato en busca de sentido. El yo no cabe en un concepto, es un misterio incluso para sí mismo. Hoy la técnica ofrece un saber para la vida, un logos sobre el hombre, pero, ¿acaso puede la razón dar respuestas definitivas a las preguntas más radicales sobre la existencia humana? Los enigmas los puede resolver la ciencia, pero los misterios no. Para P. Tillich "ser religioso significa preguntarse apasionadamente por el sentido de la vida y estar abierto a una respuesta"38. La religión suscita las preguntas más importantes del ser humano: ¿Quiénes somos? ¿De dónde venimos? ¿Qué razones nos damos para vivir? ¿Cuál es el propósito de la existencia? ¿Por qué sufrimos? ¿Existe Dios? ¿Qué hay después de la muerte? ¿Por qué morir? La ERE es un lugar privilegiado para provocar y despertar preguntas en los alumnos tratando de

36 C. Yushimito, La lectura de los afectos. Imaginación y empatía como prácticas de autodescubrimiento en el lector escolar, Biblioteca Nacional de Perú, Lima 2021.

37 J. C. Bermejo, Introducción al counselling (Relación de ayuda), Sal Terrae, Santander 2011.

38 P. Tillich, La dimensión perdida: indigencia y esperanza de nuestro tiempo, Desclée de Brouwer, Bilbao 1970, 12. 
que éstas vayan cada vez más dirigidas al terreno de lo último, de la condición humana, de la transcendencia.

Afirma la sociología de la religión que los jóvenes, al menos en occidente, ya no se dividen entre creyentes y no creyentes, sino entre buscadores y sendentarios ${ }^{39}$. Como docentes de ERE hemos de aprovechar las experiencias hondas, las búsquedas y los anhelos con los que conviven nuestros alumnos, para iluminarlas desde la fe y posibilitar la apertura a la experiencia creyente. Para ello, la mayéutica socrática y el diálogo son una buena propuesta. Para comprendernos y comprender la existencia, necesitamos dialogar con iguales. Los adolescentes están en plena construcción de su propia identidad y necesitan romper lo que han recibido para encontrarse con ellos mismos. La clase de religión puede ser un lugar privilegiado en el que mirarse por dentro y en otros -Otro- para ayudarles en el descubrimiento de lo que son, conscientes de que Jesús nos revela el misterio de Dios y el misterio del ser humano.

La vida no nos pertenece, no es un objeto o una cosa manipulable, controlable o explotable a nuestro antojo. Tampoco querer significa siempre poder ${ }^{40}$. La existencia está traspasada y sacudida por el sabor dulce de la vida y por el escalofrío de la muerte, y los jóvenes también lo saben. La dinámica del dominio y del control contrasta radicalmente con la experiencia de la propia fragilidad, que hace que todo se tambalee. No somos omnipotentes, no podemos con todo y hemos de trasmitir a nuestros alumnos que ser frágil no es malo. Como afirma Mèlich hay también una "sabiduría en lo incierto", tan próxima a la fe, que es "apertura a la incesante transformación, una transformación ambigua,

39 La diferenciación se debe a Charles Taylor. Aparece explicada en A. Grün - T. Halík, ¿Deshacerse de Dios? Cuando la fe y la increencia se abrazan, Sal Terrae, Santander 2018, 121.

40 La socióloga Eva Illouz y el psicólogo Edgar Cabanas dicen que la felicidad se ha convertido en "una obsesión", en "un regalo envenenado". Se impone una happycracia, al servicio del sistema económico actual. Alrededor de la psicología positiva florece una poderosa industria con terapias positivas, servicios de coaching o aplicaciones como Happify, que promete soluciones efectivas y basadas en la ciencia para una mejor salud emocional y mayor bienestar en el siglo XXI. E. Illouz - E. Cabanas, Happycracia. Cómo la ciencia y la industria de la felicidad controlan nuestras vidas, Paidós, Barcelona 2019. 
transgresora, sin verdades absolutas o intemporales"4l por cuanto huye de todo dogmatismo y certeza definitivas. Ante el misterio, solo cabe acercarse con humildad y fascinación, a veces, sin respuestas. En esa continua peregrinación hacia lo incierto, profesores y alumnos, hemos de cultivar la espera y, en palabras de Rilke ${ }^{42}$, "amar las preguntas":

Ten paciencia con todo aquello

que no se ha resuelto en tu corazón

e intenta amar las preguntas por sí mismas,

como si fueran habitaciones cerradas

o libros escritos en una lengua extranjera.

No busques ahora las respuestas

que no estés preparado para vivir, pues la clave es vivirlo todo.

Vive las preguntas ahora.

Tal vez las encuentres, gradualmente, sin notarlas,

y algún día lejano llegues a las respuestas.

En el claroscuro de la vida, como en la experiencia de la fe $\mathrm{e}^{43}$, hay oscuridad e interrogante, pero, sobre todo, luz y un nuevo horizonte. Vale la pena resistir, las personas sencillas lo saben, y así hemos de trasmitírselo a nuestros alumnos. En la resistencia se entrevé una extraña confianza y se descubre que la interrogación es también plegaria.

\subsection{Crear más mundo}

La tercera de las claves apunta a la capacidad de obrar el mundo que tiene el ser humano, en el sentido de re-crearlo y hacerlo nacer ${ }^{44}$. De la

41 J. C. Mèlich Sangrà, "La sabiduría de lo incierto: sobre ética y educación desde un punto de vista literario", Educar 31 (2003) 33-45, 33.

42 R. M. Rilke. Cartas a un joven poeta, Ediciones Hiperión, Madrid 2015, 6 ed.

43 Arguye G. Fourez que "la cuestión de la fe es la que se planteó Jesús cuando tuvo la impresión de que su Padre le abandonaba y cuando, a pesar de ello, tuvo confianza y puso su espíritu en sus manos". G. Fourez, La fe como confianza, Sal Terrae, Santander 2002, 46.

44 Para Esquirol el mundo entero es un inicio y el ser humano es capaz. Remitiendo a H. Arendt menciona que "lo más eminente de lo humano es la capacidad de actuar, es decir, la capacidad de empezar, de iniciar. El ser humano es el que nace y el que es capaz de hacer nacer. Ahí está la libertad: en la capacidad de iniciar algo, más allá de las leyes de la naturaleza o más allá de las inercias sociales". Esquirol, Humano, más humano, 52. 
misma manera que Jesús inició a sus seguidores en otra lógica distinta a la del poder y el comercio, la religión en las aulas permite restituir universales éticos incompatibles con la lógica capitalista y sus valores que han tomado nuestro mundo. La alternativa no proviene de la confrontación, sino de la atención a la irrupción de un nuevo tiempo y una nueva manera de vivir y convivir. Estar en este mundo como en un gran templo, ser bendición y cuidar la vida amenazada es algo que está en la entraña de la ERE, y que camina en plena consonancia con los objetivos de desarrollo sostenible y las continuas exhortaciones del papa Francisco. El cuidado y la contemplación de la belleza pueden ayudar a co-crear el mundo.

\subsubsection{El cuidado}

El desarrollo tecnológico ha contribuido a la existencia de sociedades desvinculadas, en las que cada vez está más presente la fatiga de la solidaridad y la compasión. Se multiplican los medios, los seguidores y las presencias en redes, pero se asiste a una licualización de los vínculos, también entre nuestros alumnos. Se construyen comunidades ampliadas que no tienen nada de carnal, olvidando la interdependencia. Pero nos necesitamos los unos a los otros. El cuidado forma parte de la vida:

"El cuidado emerge como posibilidad de futuro en el que dejamos venir nuestras fecundidades. Sólo desde el cuidado podremos aceptar que juntos nos salvamos; sólo desde el cuidado a los demás podremos preferir la cooperación a la competitividad, la ayuda mutua al "sálvese quien pueda", la solidaridad compasiva a la ley del más fuerte. Sólo desde el cuidado de la vida podremos educar en la humanización de nuestro mundo, en la sanación de tantas heridas abiertas, en el perdón y en la reconciliación”45.

Somos interdependientes y la proximidad nos salva ${ }^{46}$. El cuidado, que siempre ha estado presente en la vida de la escuela, en la historia de las mujeres y que tiene que ver con la propuesta del Nazareno, es una manera revolucionaria de estar en el mundo. Desde la ERE

45 Aranguren, Es nuestro momento, 30.

46 “¿Qué podrá salvarnos? Se preguntaba Heidegger; no sólo la creación artística; no sólo la oratoria política; no sólo un dios; también la proximidad y la resistencia". J. M. Esquirol, La resistencia intima: Ensayo de una filosofía de la proximidad, Acantilado, Barcelona 2015, 38. 
estamos obligados a despertar en los alumnos el dolor de la lucidez y la capacidad de obrar mundo, es decir, de hacer del mundo más mundo. En la fealdad de un mundo caracterizado por desalientos y cansancios que se manifiestan en adicciones de los más jóvenes, en guerras cruentas, en agresividad y violencia extremas, en injusticias hirientes, en soledades devastadoras, en el adormecimiento de los sueños y la falta de esperanza, y en un sinfin de formas que culminan en el desánimo que tienta a todos ante la banalidad de lo cotidiano, educar en el cuidado y reconocerse interdependiente, alumbra (da luz) al mundo.

\subsubsection{La belleza}

La fe da ojos. La clase de religión entreteje la posibilidad de ver otros mundos y de ver la belleza. Donde hay amor, hay visión. Diría Santo Tomás que:

"lo que se requiere para captar las cosas más importantes no es agudeza racional sino contemplación, espíritu atento, apertura y confianza para llenarse de lo que se nos da. Esto no es tanto tarea de la inteligencia, cuanto del amor. La sabiduría es perfección de la caridad" ${ }^{47}$.

Quizás parte de nuestro sufrimiento sea porque hemos dejado de creer en la belleza y en el bien. Es acuciante enseñar a nuestros alumnos a mirar para rescatar la belleza que le pertenece a la vida, al próximo, al mundo, para que lo invisible se nos vuelva visible. Urge despertar en los adolescentes la conciencia adormecida de su propia belleza, velada en ocasiones por el autodesprecio, o relegada al olvido por lo virtual, por las ausencias de los padres y por un ritmo de vida demasiado rápido, en el que no cabe detenerse a considerar el tesoro que son y el bien que los habita.

Muchos hombres y mujeres, que se han dejado mirar y embellecer por el más bello entre los hombres, nos proponen la fuerza de la mirada como fuente de esperanza. Unos versos de la poetisa cubana Dulce $M^{\mathrm{a}}$ Loynaz lo dicen mejor: "Me miraba un instante con su mirada capaz de embellecerme”. Es también ésta la esencia del poema Ver-

47 Tomás de Aquino, Summa Theologica, II-II, q. 9, a. 2 ad lum. 
güenza de Gabriela Mistral: "Si tú me miras, yo me vuelvo hermosa". La clase de religión entendida de este modo, no se limita a pensar a Dios y a interpretar el mundo, sino a transformarlo, rescatando y vislumbrando la novedad de la Buena Noticia que siempre es actual. Quizás el mundo siga sin hogar8, pero habremos introducido a los alumnos en un dinamismo en el que creer, esperar y amar definen aquello que es auténticamente cristiano.

48 P. Berger, Un mundo sin hogar: modernización y conciencia, Sal Terrae, Santander 1979. 